Fecha de entrega: 17 de mayo de 2010

Fecha de aprobación: 30 de junio de 2010

\title{
EMMANUEL LÉVINAS Y WALTER BENJAMIN: UNA REFLEXIÓN EN TORNO A LA NOCIÓN DE HISTORIA*
}

\author{
EMMANUEL LÉVINAS AND WALTER BENJAMIN: \\ A REFLECTION ON THE NOTION OF HISTORY.
}

\author{
María Mercedes Andrade**
}

\section{Resumen}

Este ensayo analiza algunas semejanzas y diferencias entre la obra de Emmanuel Lévinas (Totalidad e infinito y La huella del otro) y la obra de Walter Benjamin (El libro de los pasajes y 'Tesis de filosofia de la historia'). Se discute la crítica de ambos autores a la noción de totalidad, su cuestionamiento del historicismo y la exclusión de la alteridad que asocian con él, así como la propuesta de ambos autores de una noción de tiempo que rompa con la continuidad. Se discute de qué manera estas reflexiones se relacionan con la noción de responsabilidad hacia el otro.

\section{Palabras clave}

Totalidad e infinito, "Tesis de filosofia de la historia", historiografia, tiempo, responsabilidad.

\section{Abstract}

This article analyzes some similarities and differences between the works of Emmanuel Lévinas (Totality and Infinity and "Trace of the Other") and Walter Benjamin (The Arcades Project and "Theses on the Philosophy of History"). It discusses how both authors critique the notion of totality, how they question historicism and its exclusion of alterity, and how both propose a notion of time that breaks with continuity. The article discusses how these reflections are related with the notion of responsibility towardsh the other.

\section{Key words}

Totality and Infinity; "Thesis on the Philosophy of History"; historiography; time; responsibility.

\footnotetext{
Este artículo hace parte del proyecto de investigación titulado "Lecturas de Walter Benjamin", financiado por la Universidad de los Andes. Fue presentado como ponencia en las Quintas Jornadas Nacionales Emmanuel Lévinas, el 21 de abril de 2010 en la Universidad Javeriana de Bogotá.

** Profesora Asociada, Universidad de los Andes.
} 
A pesar de los muchos puntos de encuentro entre las reflexiones filosóficas de Emmanuel Lévinas y Walter Benjamin, hasta el momento este tema no ha recibido demasiada atención por parte de la crítica. Con el propósito de ayudar a corregir dicha omisión, a continuación propongo explorar la proximidad entre algunos textos de Walter Benjamin que giran en torno a la noción de historia y que fueron escritos en los años treinta y cuarenta del siglo veinte como respuesta ante la amenaza del nazismo, y algunos textos de Emmanuel Lévinas que, como bien se sabe, constituyen una reflexión ética posholocausto. Me concentraré en dos textos tardíos de Benjamin, a saber, las Tesis de filosofía de la historia (1950/1968) y El libro de los pasajes (1983), en particular en la sección titulada "Teoría del conocimiento, teoría del progreso", y en la obra de Lévinas, Totalidad e infinito (1961/1997), en especial en la sección titulada "La relación ética y el tiempo", haciendo algunas referencias al ensayo posterior, $L a$ huella del otro (1963/1986). Mi propósito es resaltar algunos puntos de convergencia entre las reflexiones de ambos filósofos, identificando de esta manera una base común a partir de la cual surgirán análisis diferentes y sin embargo afines. Me interesa discutir cómo ambas obras, desde perspectivas distintas, proponen una crítica radical de la tradición filosófica, crítica que está ligada al cuestionamiento de la comprensión moderna de la historia y que implica un compromiso profundo con la noción de alteridad.

El distanciamiento voluntario y el cuestionamiento de la tradición filosófica con la cual, sin embargo, ambos autores entran en diálogo, se hace evidente en el recurso de ambos a la tradición judía como un correctivo que permita renovar el lenguaje de la reflexión filosófica. De hecho para Lévinas, la oposición entre la figura de Odiseo y la de Abraham ilustra claramente el cambio que su filosofía propone: "al mito de Ulises retornando a Ítaca queremos oponer la historia de Abraham, quien deja su patria para siempre por una tierra aún desconocida" (Lévinas, 1963/1986, p. 348) ${ }^{1}$. Para Lévinas la actitud de Ulises simboliza la actitud de la filosofía, para la cual todo contacto con la otredad está orientado a un retorno a casa, a una conquista de la alteridad, a la reducción del otro al mismo. En contraste, el "movimiento sin retorno" (p. 347) que Lévinas propone consiste en un abrirse por completo al Otro en un gesto que es a la vez de bienvenida y de deseo. Por otra parte, Benjamin también se remonta a la tradición judía, cuyo lenguaje adopta de forma deliberada. Así, en la obra de Benjamin términos como los de "iluminación" (si bien profana), la llegada del Mesías, el juicio y la redención, aparecen con frecuencia, aunque el estatus de estas nociones continúe siendo motivo de discusión ${ }^{2}$.

Lévinas y Benjamin coinciden también en el rechazo del sistema filosófico y de la idea de totalidad, rechazo que está relacionado con la influencia que sobre los dos ejerció la obra de Franz Rosenzweig, La estrella de la redención ${ }^{3}$. En Totalidad e infinito, la

1 Todas las traducciones de textos consultados en inglés y en alemán son mías.

2 Michael Löwy, en Walter Benjamin: Aviso de incendio resume el debate entre académicos ocurrido en los años cincuenta, acerca de cómo interpretar las "Tesis de filosofía de la historia": algunos reclamaban a Benjamin como marxista, argumentando que las referencias a la teología judía eran metafóricas, otros lo reclamaban como teólogo, mientras que un tercer grupo consideraba que Benjamin intentaba hacer una síntesis entre ambas corrientes (p. 41).

3 Dice Lévinas en Totalidad e infinito: "La oposición a la idea de totalidad nos ha impresionado en el Stern der Erlösung de Franz Rosenzweig, demasiado presente en este libro como para ser citado" (1961/1997, p. 54). Asimismo, Benjamin menciona la obra de Rosenzweig numerosas veces en sus cartas. En una carta a Alfred Cohn dice sobre la obra que "en una época estuve embelesado con ella” (1978/1994, p. 494). 
preocupación por la otredad está ligada a un abandono expreso del proyecto de dar cuenta de la totalidad, noción que para Lévinas está relacionada con la guerra, puesto que en la totalidad "la unicidad de cada presente es sacrificada incesantemente a un porvenir convocado a despejar su sentido objetivo" (Lévinas, 1961/1997, p. 48). En el caso de Benjamin, la escritura a base de fragmentos o de citas difiere también radicalmente de la obra monumental que funda el sistema filosófico. Así, en textos como el Libro de los pasajes Benjamin reúne citas y fragmentos que yuxtapone de una manera que se asemeja a la técnica surrealista del montaje, la cual consideraba como paradigmática, de tal forma que, según él, el significado del texto se le revelará al lector en una "iluminación profana": "el método de esta obra: el montaje literario. No tengo nada qué decir, sólo qué mostrar" (1982, p. 574). Con este método Benjamin pretende sacar lo familiar de su contexto y reinscribirlo dentro del montaje de manera que produzca un "efecto de shock" que libere las fuerzas subversivas de aquello cuyo significado se ha domesticado bajo la fuerza del hábito. Este ímpetu es afín al de Lévinas quien propone que, con el cuestionamiento de la idea de totalidad, "restituye a cada instante su plena significación” (1961/1997, p. 49).

\section{La historia como exclusión}

El cuestionamiento de Lévinas y Benjamin de la noción de totalidad está dirigido a un replanteamiento de la concepción de la historia característica del historicismo, así como a la noción de progreso que con ella se asocia. En la sección de Totalidad e infinito titulada "La relación ética y el tiempo", Lévinas presenta su crítica del historicismo y de la noción de una historia universal. La historia es totalitaria porque no establece relación una voluntad, sino que opera en retrospectiva, relacionándose tan sólo con las obras que aquella voluntad ha dejado. Lévinas ha mostrado cómo el trabajo, y con él las obras del Yo, son cruciales para permitirle lograr estar "en lo de sí" (p. 226), o "en casa", ya que el Yo se apodera del mundo a través del trabajo, encontrando de esta manera un lugar para sí y un hogar (p. 61) ${ }^{4}$. Sin embargo, las obras son diferentes a la voluntad, pues son externas a ella. Las obras de la voluntad no son ella y, en tanto que externas y materiales, se prestan para la apropiación del otro: "la obra no se defiende contra el Sinngebung del otro y expone la voluntad que la ha producido a la discusión y al desconocimiento, se ofrece a los designios de una voluntad extranjera y se deja apropiar" (p. 240). La historia se ocupa de eventos, de lo visible y de lo material, y no de la interioridad de esa voluntad, a la cual no tiene acceso. Las obras en cambio pueden ser observadas, tematizadas e interpretadas al punto de que pueden traicionar la voluntad que las produjo, y convertirse en cómplices de la interpretación de otro. Para Lévinas la historia no puede decir nada sobre la interioridad de la voluntad, sino que tan solo puede documentar la manera como sus obras han sido dominadas por aquellos que la escriben: "la historiografía narra el modo como los sobrevivientes se apropian de las obras de voluntades muertas; reposa sobre la usurpación llevada a cabo por los vencedores, es decir, por los sobrevivientes; narra la servidumbre al olvidar la vida que lucha contra ella" (p. 241). La historia opera en la distancia, aquella distancia que para Lévinas se identifica con la violencia que está a la base de la filosofía. Recuérdese que en el prefacio a Totalidad e infinito Lévinas ha hablado del impulso totalitario de la filosofía occidental, por medio del cual "los individuos son meros portadores de fuerzas que los guían dirigen a sus espaldas. Toman prestado un sentido a

4 Alphonso Lingis traduce "chez soi" por "being at home with itself" ("estar en casa consigo mismo"), en la versión en inglés de Totalidad e infinito (Lévinas 1961/1969, p. 37). 
esta totalidad" (p. 48). Así, en la construcción histórica las obras se interpretan como el desarrollo de una sola idea, de una totalidad, y se olvidan las voluntades que las produjeron. Para Lévinas, la injusticia hacia la voluntad dominada es la base de toda historiografía.

La semejanza entre la posición de Lévinas y la crítica de Benjamin al historicismo resulta sorprendente. Como afirma Hannah Arendt, Benjamin se preocupa por el problema de la tradición y la manera como la tradición se relaciona con el pasado, llevándolo a "cuestionar la relevancia de la tradición occidental como tal" (1968, p. 37). Para Benjamin, la tradición presenta al pasado, dándole una apariencia de coherencia, ejerciendo su autoridad para dominar lo ocurrido. Utilizando el lenguaje de Lévinas se podría decir que la tradición ofrece una apariencia de totalidad, y para romper con esta totalidad es necesario interrumpir el engañoso curso de la tradición. Para Benjamin, esto se lograría, entre otros, a través del método del montaje mencionado anteriormente. Así, en una obra como El libro de los pasajes, los fragmentos de textos históricos se ordenan de manera que escapan a la interpretación habitual. Para Arendt, este método estaba basado en "la idea implícita de que el pasado sólo podía hablar directamente a través de cosas que no habían sido transmitidas de mano en mano" (p. 40). En la obra de_Benjamin esta actitud la ejemplifica la figura del coleccionista, en quien se conjugan la reverencia hacia el pasado y su subversión. En la sección del Libro de los pasajes titulada "El coleccionista" Benjamin afirma que "lo decisivo al coleccionar es que el objeto sea separado de todas sus funciones originales, para que pueda entrar en la relación más estrecha posible con sus semejantes". Así el objeto/fragmento/cita adquiere un nuevo sentido en "un nuevo sistema histórico creado, la colección” (p. 271).
Para Lévinas, tanto como para Benjamin, la historia la escriben los vencedores. En la Tesis VII de las "Tesis de filosofía de la historia” Benjamin afirma que
quienquiera que haya conducido la victoria hasta el día de hoy partici- pa en el cortejo triunfal en el cual los dominadores de hoy pasan por encima de aquellos que hoy yacen en tierra. La presa, como ha sido siempre costumbre, es arrastrada en el triunfo. Se la denomina con la expresión: patrimonio cultural [...]. No existe documento de cultura que no sea a la vez documento de barbarie" (p. 81).

La historia, como la concibe la historiografía, es también un instrumento del totalitarismo, y por tanto una negación del Otro por parte del vencedor. Al igual que Lévinas, Benjamin ve que la historia proporciona una justificación para la violencia que se ejerce contra una voluntad que no participa en su escritura.

\section{Un tiempo discontinuo}

Tanto para Lévinas como para Benjamin la crítica de la historiografía implica un cuestionamiento de la creencia en la continuidad de la historia. En Benjamin esto está relacionado con la crítica del totalitarismo ante la amenaza del Nazismo, contra el cual están dirigidas las Tesis, así como con la crítica de la manera como el Nazismo utilizó la noción de progreso como justificación para sus actos. En el caso de Lévinas, se trata de una crítica retrospectiva, una reflexión sobre ese mismo momento de peligro del cual habla Benjamin. Por supuesto, en ninguno de los dos casos se limita la reflexión a este contexto específico.

Lévinas presenta la idea de un tiempo discontinuo en relación con la noción de escatología en el prefacio de Totalidad e infinito. Si bien 
Lévinas cuestiona la escatología religiosa en tanto que "adivinación subjetiva y arbitraria del futuro" (p. 48), le sirve de modelo en tanto que "no introduce el sistema teológico en la totalidad, no consiste en enseñar la orientación de la historia. La escatología pone en relación con el ser más allá de la totalidad" (p. 49). Para él, la escatología y su noción del juicio rompen con el continuo de la historia y sacan cada instante de su fluir teleológico: "sometiendo a juicio a la historia en su conjunto, exterior a las mismas guerras que marcan su fin, restituye a cada instante su plena significación en ese mismo instante: todas las causas están maduras para ser entendidas" (p. 49). La apariencia de totalidad se rompe y cada momento se juzga por fuera de ella. Aunque Lévinas no lo pone en estos términos, esta reflexión podría interpretarse como una crítica de la idea de progreso ya que el "mito" del progreso, para usar el lenguaje de Benjamin, implica una teleología de la historia.

En la sección de Totalidad e infinito titulada "La relación ética y el tiempo" Lévinas se ocupa directamente de la cuestión de la continuidad de la historia desde el punto de vista de la voluntad y considerando nuevamente la noción de juicio. Afirma que la idea de un tiempo continuo en la cual se basa la historia, se interrumpe gracias a la voluntad y su presencia en el juicio: "los acontecimientos históricos son lo visible por excelencia. Lo visible forma una totalidad o tiende a ella. Excluye la apología que deshace la totalidad al insertar en ella, en todo momento, el presente, el insuperable, inenglobable de su subjetividad misma" (p. 257). En el juicio, en la apología, la voluntad está presente ante el Otro y se rompe la distancia histórica. Sólo la presencia del Otro rompe la ilusión de totalidad. Para Lévinas el tiempo es ese "aún no", el aplazamiento de la muerte, y por tanto cada instante está ligado a la resurrección. En lugar de la continuidad, "la resurrección constituye el acontecimiento principal del tiempo. No hay pues continuidad en el ser. El tiempo es discontinuo. Un instante no sale de otro sin interrupción, por un éxtasis. El instante, en su continuación, encuentra la muerte y resucita. Muerte y Resurrección constituyen el tiempo" (p. 291). Así, si bien ambos autores proponen una ruptura de la continuidad, en Benjamin se trata de un gesto que se dirige hacia el pasado, mientras que en Lévinas el énfasis recae en la proyección hacia el futuro.

A pesar de esta diferencia, la concepción del tiempo de Lévinas se aproxima a la comprensión de Benjamin del tiempo como "tiempo actual” (Jetztzeit) (1950/1971, p. 86). En la Tesis XVI, Benjamin afirma que "el materialista histórico no puede renunciar al concepto de un presente que no es tránsito sino que es inmóvil y se halla en equilibro en el tiempo" (p. 87). En lugar de la continuidad de la historia Benjamin nos presenta la imagen del ángel de la historia, quien se encuentra ubicado en el "tiempo actual" o "tiempo del ahora" desde donde observa el pasado. El pasado no aparece ante sus ojos como un continuo sino como una sola catástrofe, una colección de desechos. Con esta imagen Benjamin se opone a lo que él caracteriza como la concepción de la historiografía moderna, que para él consiste en acumular objetos como cuentas en un rosario (p. 89) para llenar un "tiempo homogéneo y vacío" (p. 86), y según la cual el presente es sólo un instante pasajero orientado hacia el futuro de manera lineal.

Peter Osborne señala que la noción de Jetztzeit de Benjamin no es la del instante ni la de "el presente fenomenológico extendido, duracional" (1994, p. 86), sino que "aspira en cambio a concentrar es su espacio puntual, unidimensional, no sólo un contenido histórico longitudinal sino la presencia de la historia toda, refractada a través del prisma del presente histórico" (p. 86). En el "tiempo actual", "cuando el pensamiento se detiene de golpe” (p. 88), según Benjamin, el pasado y el 
presente entran en una "constelación cargada de tensiones" (p. 88), que permiten que el pasado, por decirlo así, "resucite" mediante su conexión revolucionaria con el ahora.

Es aquí donde surge una diferencia fundamental entre el pensamiento de Lévinas en Totalidad e infinito y el de Benjamin. Para Lévinas la historia se dice en tercera persona, nunca en la primera: "el juicio de la historia se pronuncia siempre por contumacia. La ausencia de la voluntad en este juicio consiste en que no está presente en él más que como tercera persona" (1961/1997, p. 256), dice Lévinas. La única manera de evitar la totalización en la cual se basa la historia es en el diálogo, en el juicio, en el cual la voluntad está presente de manera apologética (p. 257). Para Lévinas el juicio instaura la responsabilidad infinita hacia el otro. Esta preeminencia de la presencia, sin embargo, no parece permitir en Totalidad e infinito una relación con el pasado. El ensayo "La huella del Otro", sin embargo, es en cierto sentido una revisión de dichas ideas, que permite una nueva relación con el pasado y con la ausencia. Esto se logra, específicamente, a través de la noción de "huella". Para Lévinas, el Otro, "que se manifiesta en el rostro" (1963/1986, p. 351) se presenta como alguien que proviene "de más allá" (p. 354). Ésta es una nueva manera de afirmar lo que ya se había dicho en Totalidad e infinito, es decir, que el Otro es trascendente con respecto al Yo, ya que lo radicalmente otro escapa la tematización: “el rostro se niega a la posesión, a mis poderes" (1961/1997, p. 211). En el ensayo "La huella del Otro", el otro aparece como "más allá del mundo, es decir, más allá del develamiento" (1963/1986, p. 354).

Si el rostro viene de un más allá que no puede ser develado, no puede ser tematizado, entonces viene de aquello que está ausente en un sentido absoluto, que para Lévinas es "un pasado absolutamente pasado" (p.
357), y por tanto "el rostro es la huella de lo radicalmente pasado" (p. 355). Siguiendo a Jill Robbins, esto significa que "la alteridad ocurre como un pasado que no está disponible para ningún presente, es un pasado absoluto" (1995, p. 177). La huella, según Lévinas, “significa más allá del ser" (1963/1986, p. 356), se refiere a algo que está más allá del mundo. Para Lévinas, ese "algo" de donde proviene el Rostro es "la ausencia suprema e irreversible” (1963/1986, p. 356).

\section{La responsabilidad hacia el Otro}

La noción de responsabilidad ocupa un lugar central en las reflexiones tanto de Benjamin como de Lévinas. En el caso de Lévinas, la libertad, el disfrute del yo, es cuestionado por la aparición del rostro del Otro: en su indigencia absoluta, "el Otro se impone como una exigencia que domina esta libertad, y a partir de aquí, como más original que todo lo que pasa en mí" (1961/1997, p. 109). Su presencia cuestiona al Yo y le impone "exigencias infinitas" (p. 259). El Yo abandona su posición de egoísmo, según la cual se apropia del mundo para lograr su disfrute, y al rendirse ante el Otro entra en una dimensión de responsabilidad que nunca se satisface, pues “entre más encaro mis responsabilidades, más responsable soy” (1963/1986, p. 354).

Siguiendo a Bernhard Waldenfels "la idea tradicional de responsabilidad significa que dondequiera que se hace y dice algo, todo el mundo habla con su propia voz, y en la propia voz la voz universal de la razón encuentra su expresión" (1995, p. 40). Esta idea culminaría en la noción de responsabilidad personal: yo soy responsable de algo ante alguien. Sin embargo, Lévinas habla de una responsabilidad totalmente diferente. Para Waldenfels, "este nuevo tipo de responsabilidad no se limita a dar razones; en cambio [...] como superabundancia de responsabilidad no descansa en ningún resultado" (p. 41). La responsabilidad 
ocurre en la apología, donde el yo incapaz de eludirla se disculpa ante el otro: "no poder ocultarse: he aquí el yo" (1961/1997, p. 259). En contraste con Benjamin, Lévinas no elabora la relación entre responsabilidad y acción. La mención de la responsabilidad de "servir al pobre, al extranjero, a la viuda y al huérfano" (p. 259) sugiere que Lévinas reconoce dicha conexión, pero dado que se trata de metáforas dentro del texto, la cuestión no parece quedar resuelta.

Aunque en Totalidad e infinito la responsabilidad sin fin es una dimensión que se abre a través del encuentro con el Otro, en $L a$ huella del Otro Lévinas extiende esta responsabilidad más allá del plano de la presencia y se convierte en una responsabilidad hacia la huella. Si la formulación se dirige hacia la huella, según Jill Robbins, se sigue que "no se puede decir que el otro por quien soy responsable esté allí. La huella por medio de la cual el rostro del otro significa está por fuera de la díada presencia-ausencia, y por lo tanto el otro no puede ser concebido en términos de una metafísica de la presencia" (1995, p. 178).

Para Benjamin la responsabilidad hacia el Otro también se orienta hacia el pasado y hacia una ausencia, pues según él el ahora es responsable de aquello que lo precede. Según Benjamin, el "sueño" que adormece a la modernidad es su incapacidad de establecer una relación con el pasado más allá de la abstracta y vacía que se critica en las Tesis. En contra de esta visión abstracta del pasado, en la Tesis II Benjamin afirma que "el pasado contiene un índice temporal que lo remite a la salvación. Hay un secreto acuerdo entre las generaciones pasadas y la nuestra. Hemos sido esperados en la tierra. A nosotros, como a las generaciones que nos precedieron, nos ha sido dada una débil fuerza mesiánica sobre la cual el pasado tiene derecho" (1950/1971, p. 78).
La responsabilidad del presente con respecto al pasado tiene que ver, para Benjamin, con el acto de recordar: "sólo en la imagen, que relampaguea de una vez para siempre en el instante de su cognoscibilidad, se deja fijar el pasado... Puesto que es una imagen irrevocable del pasado, que corre el riesgo de desvanecerse para cada presente que no se reconozca en ella" (p. 79). Ante esta amenaza el acto de recordar abre una posibilidad de redención. A través de la memoria, los excluidos y manipulados reciben justicia. Simultáneamente, el presente se redime al adquirir una visión nueva del pasado que le permita romper con el mito del progreso mediante el cual el presente aparece como siempre nuevo.

Es aquí donde entra en juego la noción de "imagen dialéctica", el concepto clave del Libro de los pasajes. Para Benjamin, la imagen dialéctica resulta de la yuxtaposición de citas de textos históricos y actuales, y da una imagen del pasado que no se asemeja a aquella transmitida por la tradición, permitiendo así una nueva interpretación tanto del pasado como del presente. Para Benjamin, en la imagen dialéctica el presente y el pasado se relacionan de manera que producen una “constelación" de sentido, permitiendo reconocer la relevancia de eventos que aparentemente no tendrían conexión con el presente. Dice Benjamin: "no es que el pasado lance su luz sobre el presente o que el presente lance su luz sobre el pasado. En cambio, una imagen es aquella en la cual lo ocurrido entra con un relámpago en una constelación con el ahora. [...] Sólo las imágenes dialécticas son verdaderas imágenes; y el lugar donde se las encuentra es el habla" (1983, p. 577).

La imagen dialéctica es entonces un tipo de escritura, y la relación con el pasado que surge en los textos de Benjamin sería entonces un acto de lectura. En esto Benjamin se diferencia de Lévinas, al menos en lo propuesto 
en Totalidad e infinito, donde se privilegia esa experiencia directa del encuentro con el otro y todo acto de lectura se caracterizaría más bien como una relación con las "obras" del otro, relación que, como hemos visto, se presta a la apropiación del otro por el mismo. Quizás la noción de huella que aparece en La huella del Otro sería más cercana a lo propuesto por Benjamin, ya que ésta permite pensar la relación con una ausencia.

A pesar de las diferencias, es posible afirmar que tanto para Lévinas como para Benjamin la relación con el otro implica ante todo una responsabilidad que el individuo debe asumir en un instante determinado, ya sea ante un pasado que se revela en el "instante de su cognoscibilidad", o ante la presencia del otro que rompe con la totalidad. En ambos casos, la responsabilidad se relaciona con un rechazo de la totalización histórica, que implica remitirse a lo individual e irrepetible de la experiencia del instante.

\section{Referencias}

Arendt, H. (1968). "Introduction: Walter Benjamin: 1892-1940”. En Benjamin, W. Illuminations. (pp. 1-55). New York: Shocken Books.

Benjamin, W. (1950/1971). Tesis de filosofía de la historia.

Benjamin, W. (1978/1994). The Correspondence of Walter Benjamin: 1910-1940. Chicago: University of Chicago Press.

Benjamin, W. (1983). Das Passagen-Werk. Suhrkamp Verlag, Frankfurt am Main.

Benjamin, W. (s.f.) Angelus Novus. Barcelona: Edhasa.
Buck-Morss, S. (1970). Dialectics of Seeing; Walter Benjamin and the Arcades Project. New York: Holt, Rinehart, and Winston.

Buck-Morss, S. (1977). The Origin of Negative Dialectics: Theodor W. Adorno, Walter Benjamin and the Frankfurt Institute. New York: The Free Press.

Lévinas, E. (1963/1986). The Trace of the Other. Alphonso Lingis. (Trad.). En Taylor, M. (Ed.). (1986). Deconstruction in Context. (pp. 345-359). Chicago: University of Chicago Press.

Lévinas, E. (1961/1997). Totalidad e infinito. Salamanca: Sígueme.

Lévinas, E. (1961/1969). Totality and Infinity. Pittsburgh: Duquesne UP.

Osborne, P. (1994). "Small-scale Victories, Large-scale Defeats". Benjamin, Andrew and Osborne, Peter (Eds.) (1994). Walter Benjamin's Philosophy: Destruction and Experience. (pp. 59-109). New York: Routledge.

Robbins, J. (1995). Tracing Responsibility in Lévinas's Ethical Thought. Peperzak, Adriaan (Ed.) (1995). Ethics as First Philosophy; The Significance of Emmanuel Lévinas for Philosophy, Literature and Religion. (pp. 173-183). London: Routledge.

Waldenfels, B. (1995). Response and Responsibility in Lévinas. Peperzak Adriaan (Ed.) (1995). Ethics as First Philosophy; The Significance of Emmanuel Lévinas for Philosophy, Literature and Religion. (pp. 39-52). London: Routledge. 